\title{
The Impacts of Electric Strengths Between AC Buses on Sub-synchronous Resonance
}

\author{
Haifeng $\mathrm{Li}^{1, *}$, Mengke Liao ${ }^{1}$, Xinfu Song ${ }^{1}$, Shaoran Wang ${ }^{2}$, $\mathrm{Lin} \mathrm{Fu}^{1}$ and Hongyang $\mathrm{Yu}^{3}$ \\ ${ }^{1}$ State Grid Xinjiang Electric Power Co. Ltd. Economic Research Institute, Urumqi, 830000, China \\ ${ }^{2}$ State Grid Xinjiang Electric Power Co. Ltd., Urumqi, 830000, China \\ ${ }^{3}$ State Key Laboratory of Advanced Transmission Technology (Global Electricity Interconnection Research Institute Co. Ltd) \\ Beijing, 102209, China \\ ${ }^{*}$ Corresponding author
}

\begin{abstract}
This paper analyzes relationship between electric strengths and the risk of sub-synchronous resonance (SSR). Firstly, the compensation impact factor (CIF) method is used to replace the process of determining sub-synchronous damping characteristics of an AC system. Then the risk of SSR can be reflected by the CIF indicator and the relationship between electric strength and CIF is obtained. Finally, a proper electric strength range is drawn at a planning stage for the AC system. The proposed analysis method does not need too much computation resource and have an excellent accuracy. Simulation results show that CIF indicates the risk of SSR when electric strengths between AC Buses changes and the proper range of electric strength can avoid the threats of SSR for the AC system.
\end{abstract}

Keywords-sub-synchronous resonance; electric strenght; compensation impact factor; sub-synchronous damping characteristics

\section{INTRODUCTION}

Series compensation using fixed capacitor is an economic and practical option for enhancing power transmission capacity and transient stability for a long-distance AC transmission system [1-4]. However, sub-synchronous energy will be excited between thermal plants and series compensators and threats the systems [5-8]. The grid structure and electric strength have effects on damping the sub-synchronous resonance (SSR) as the resonance frequency changes with different grid structure and electric strength [9]. Therefore, SSR could be avoided if the electric strengths between AC Buses are within a proper range.

The existing literatures [10-15] analyzing SSR cost too much computation resource and are lack of accuracy. Frequency scanning method [10-11] can determine the system resonance frequency without high request of computation resource. However, this method is unable to get subsynchronous damping characteristics to evaluate the impact of electric strength on SSR. Therefore, the accuracy of frequency scanning method is insufficient to determine the risk of SSR. Eigenvalue [12-13] and test signal [14-15] methods can obtain the sub-synchronous damping characteristics but they require extensively computation works. [16] proposes a compensation impact factor (CIF) method to determine risk of SSR by analyzing the relationship between sub-synchronous damping characteristics and CIF indicators. Therefore, this method can demonstrate how electric strength affects SSR, if the relationship between CIF and electric strength can be determined.

This paper uses the CIF method to evaluate the impacts of electric strengths between AC Buses on SSR. Firstly, the relationship between CIF and electric strength are discussed to imply how CIF changes with variation of the electric strengths. Then the CIF, rather than the sub-synchronous damping characteristics, is used to evaluate the risk of SSR. As a result, the analysis process of SSR is quite simple and the accuracy are sufficient. Finally, a proper range of electric strength is obtained for a system planning stage. Two main advantages are drawn from this paper, i.e., 1) the SSR analysis process by using CIF would be simple without too much computation resource, and 2) a proper electric strength range can be determined at system planning stage.

The rest of this paper are organized as follows, Section II introduces the CIF method briefly. Section III analyzes the relationship between electric strengths and SSR by calculating damping characteristics. Section IV validates the proper electric strength range and Section V draws conclusions of this paper.

\section{THE COMPENSATION IMPACT FACTOR}

CIF [16] is the method to evaluate the risk of SSR caused by fix compensation capacitor for thermal generators. The calculation of CIF needs little information on generator shafts. Therefore the equivalent model for an AC system is quite simple, considering using power source model for the generators. Figure 1 shows active power, which are divided into "causing disturbance group" and "restraining disturbance group”, for computing CIF for a generator.

In Figure 1, the generator connects to the system through a compensated line and $N$ non-compensated lines. The "noncompensated line" represents the parallel path to the compensated line. $P_{C}$ is the active power flow in the compensated line while $P_{U C-1}$ through $P_{U C-N}$ represents the active power flow going through each non-compensated line respectively. The positive directions of these active power flows are shown in Figure 1.

The definition of CIF is shown in (1). Assuming that a fault happens at $t_{1}$ and then the system recovers to the steady state at 
$t_{2}$, if the active power of the causing disturbance group line can be offset perfectly by those of the restraining disturbance group line, then the sub-synchronous disturbance energy has no path to reach the generator end. Hence, there is no interaction energy exchanged between the generator shaft and compensation capacitor, and the generator will not be under any SSR threat.

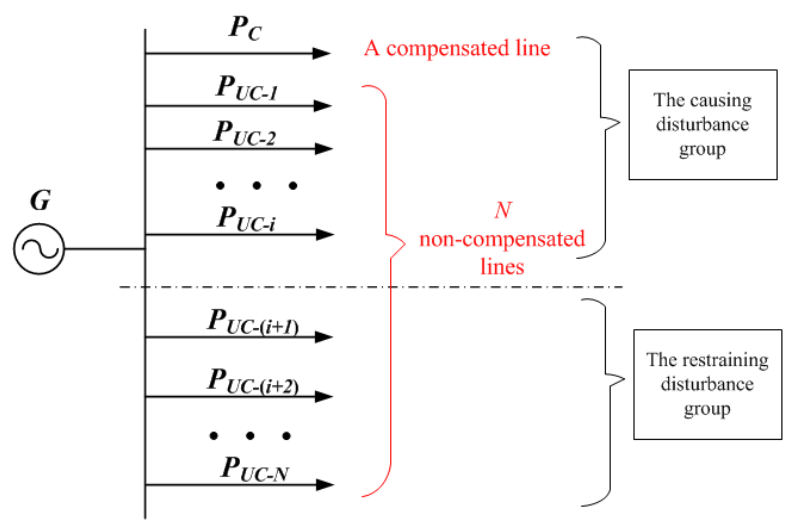

FIGURE I. ACTIVE POWER FOR COMPUTING CIF

$C I F=\left|\frac{\left[\max _{t \in\left[t_{1}, t_{2}\right]} P_{C}(\mathrm{t})-P_{C}\left(\mathrm{t}_{1}\right)\right]+\sum_{j=1}^{i}\left[\max _{t \in\left[t_{1}, t_{2}\right]} P_{U C-j}(\mathrm{t})-P_{U C-j}\left(\mathrm{t}_{1}\right)\right]}{\sum_{k=i+1}^{N}\left[P_{U C-k}\left(\mathrm{t}_{1}\right)-\min _{t \in\left[t_{1}, t_{2}\right]} P_{U C-k}(\mathrm{t})\right]}-1\right|$

However, in practical scenario, CIF is not always equal to 0 . But it does not mean that SSR will occur. Therefore, [16] gives a threshold value $T_{C I F}=0.2$ to forecast that there is no SSR threat for the generator if $\mathrm{CIF}<\mathrm{T}_{\mathrm{CIF}}$.

\section{The Relationship BETWEen Electric StRENGTH AND CIF}

\section{A. Test System}

Since the threshold value $T_{C I F}$ of CIF indicator is obtained from sub-synchronous damping characteristics, the risk of SSR can be reflected by the CIF indicator and then the calculation process is simple and convenient as (1) shows. For analyzing the relationship between electric strength of an AC system and CIF, a standard test system is shown in Figure 2.

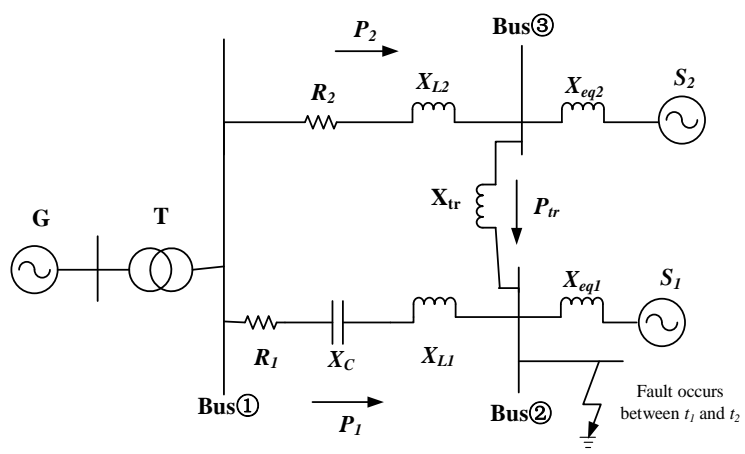

FIGURE II. THE STANDARD TEST SYSTEM
Figure 2 shows a 3-bus AC system which demonstrates the interactions between the compensated line and noncompensated one when a fault happens. Compensated line is in the causing disturbance group while the uncompensated line belongs to the restraining disturbance group. The fault at Bus (2) creates a disturbance with a wide frequency range which includes the sub-synchronous component which guarantees that any potential risk for exciting SSR is captured by the simulation. As Figure 2 shown, $G$ is a generator and $T$ represents transformers. $S_{1}\left(S_{2}\right)$ is an equivalent system which is connected to Bus(2) (Bus(3) with its equivalent reactance $X_{e q 1}\left(X_{e q 2}\right)$. The reactance $X_{t r}$ represents the electrical strength between Bus(2) and Bus(3). $P_{t r}$ is the active power flowing through $X_{t r} . R_{1}, X_{L 1}$ and $X_{C}$ are the resistance, inductive reactance and capacitive reactance of the compensated transmission line, respectively. $R_{2}$ and $X_{L 2}$ represent the resistance and reactance of the non-compensated line. $P_{1}$ and $P_{2}$ are the active power flowing through the compensated and non-compensated transmission lines respectively.

The parameters of the test system are listed in Table 1 . The change of $X_{e q 1}, X_{e q 2}$ and $X_{t r}$ can simulate the change of electric strengths among Bus(1) to Bus(3). Table 2 shows the variation range of $X_{\text {eq1 }}, X_{\text {eq } 2}$ and $X_{t r}$ and the step is 0.01 p.u..

TABLE I. PARAMETERS OF THE EQUIVALENT SYSTEM

\begin{tabular}{|c|c|c|c|c|c|c|c|}
\hline $\begin{array}{c}\mathrm{S}_{\mathrm{B}} \\
(\mathrm{MVA})\end{array}$ & $\begin{array}{c}T \\
(\mathrm{kV})\end{array}$ & $\begin{array}{c}X_{T} \\
\text { (p.u.) }\end{array}$ & $\begin{array}{c}R_{1} \\
(\mathrm{pu})\end{array}$ & $\begin{array}{c}R_{2} \\
(\mathrm{pu})\end{array}$ & $\begin{array}{c}X_{L 1} \\
(\mathrm{pu})\end{array}$ & $\begin{array}{c}X_{\mathrm{L} 2} \\
(\mathrm{pu})\end{array}$ & $\begin{array}{c}X_{C} \\
(\mathrm{pu})\end{array}$ \\
\hline 892.4 & $26 / 539$ & 0.14 & 0.02 & 0.005 & 0.417 & 0.213 & 0.204 \\
\hline
\end{tabular}

Note: $S_{B}=892.4 \mathrm{MVA}, V_{B}=539 \mathrm{kV}$.

TABLE II. THE CHANGING RANGE OF THE $X_{E Q 1}, X_{E Q 2}$ AND $X_{T R}$

\begin{tabular}{|c|c|c|c|}
\hline Parameter & $X_{\text {eq1 }}(\mathrm{pu})$ & $X_{\text {eq2 }}(\mathrm{pu})$ & $X_{t r}(\mathrm{pu})$ \\
\hline Range & $0 \sim 0.5$ & $0 \sim 0.5$ & $0 \sim 1$ \\
\hline
\end{tabular}

Note: $S_{B}=892.4 \mathrm{MVA}, V_{B}=539 \mathrm{kV}$.

\section{B. CIF and Electric Strength}

When $\left(X_{e q 1}, X_{e q 2}, X_{t r}\right)$ changes as Table 2 listed, CIF of the generator of Figure 2 is calculated in Figure 3 . CIF is demonstrated by colors whose value is shown as color bars.

Figure 3(a) shows that when $X_{\text {eq2 }}$ is fixed, lower values of $X_{e q 1}$ and $X_{t r}$ result in a lower CIF value for the generator. Therefore, strong electric strengths between Bus(1) and Bus(2) and between Bus(2) and Bus(3) assist to avoid SSR risk. When $X_{e q 2}$ becomes larger, the risk of SSR grows since the area of CIF $>0.2$ increases.

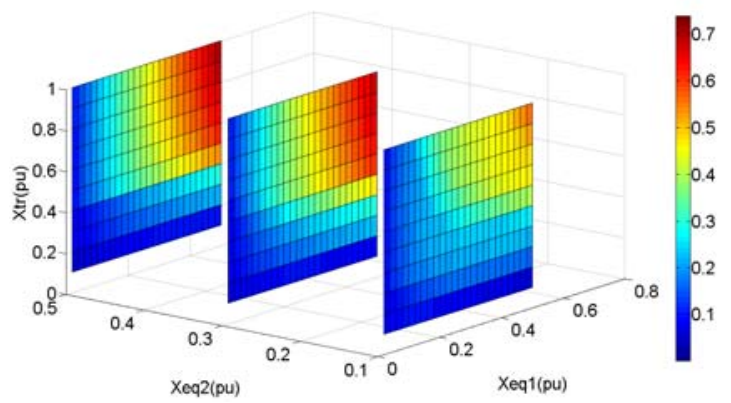

(a) The fragment surface of CIF when $X_{\text {eq } 2}=0.1,0.3,0.5$ p.u. 


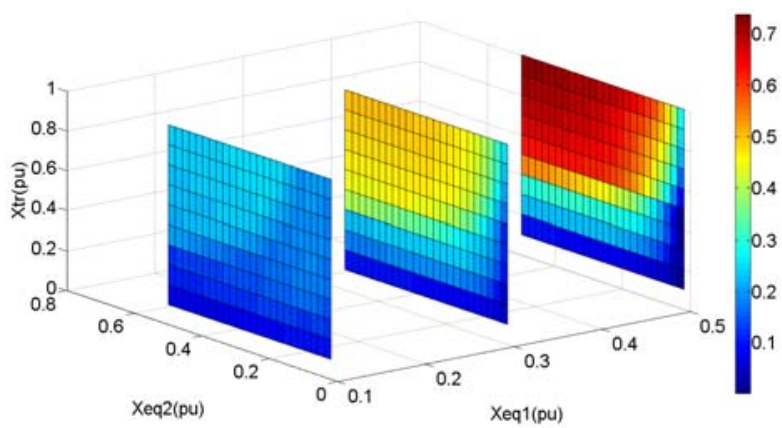

(b) The fragment surface of CIF when $X_{\text {eq1 }}=0.1,0.3,0.5$ p.u.

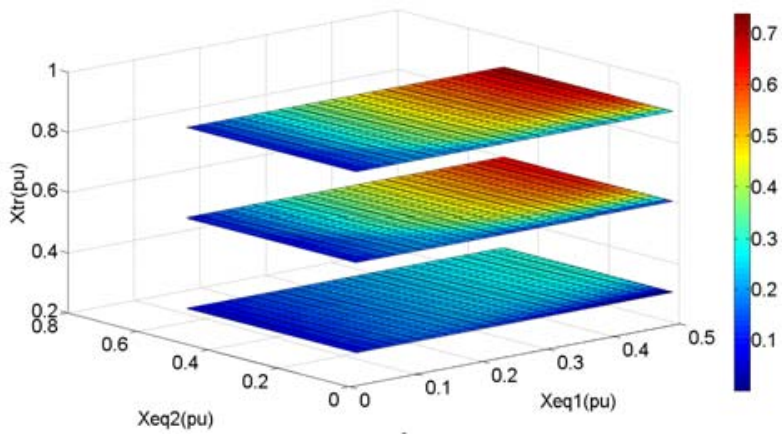

(c) The fragment surface of CIF when $X_{t r}=0.2,0.6,0.8$ p.u.

FIGURE III. THE CIF WHEN ELECTRIC STRENGTH CHANGES

Figure 3(b) shows that when $X_{\text {eq1 }}$ is fixed, lower values of $X_{\text {eq2 }}$ and $X_{t r}$ obtain a lower CIF value for the generator. Therefore, strong electric strengths between Bus(1) and Bus(3) and between Bus(2) and Bus(3) are helpful to reduce SSR risk. Compared FIGURE III(a) with FIGURE III(b), SSR risk area is more sensitive with the change of $X_{\text {eq1 }}$ rather than the change of $X_{\text {eq2 }}$.

Figure 3(c) shows that when $X_{t r}$ is fixed, lower values of $X_{\text {eq1 }}$ and $X_{\text {eq2 }}$ produce a lower CIF value for the generator. Therefore, strong electric strengths between Bus(1) and Bus(2) and between Bus(1) and Bus(3) can eliminate the risk of SSR. When $X_{\text {tr }}$ increase from 0.2 to 0.6 p.u., SSR risk area increases significantly. However, when $X_{t r}$ continuously increasing, the SSR risk area is not changing obviously.

Therefore, strong electric strength between AC Buses are helpful to eliminate SSR risk for the generator. In the system shown in Figure 2, $X_{\text {eq1 }}$ and $X_{\text {tr }}$ affects the SSR risk more obviously than $X_{\text {eq2 }}$.

\section{Simulation Tests}

\section{A. Damping Characteristics}

The test system in Figure 2 is adopted here to show the subsynchronous damping characteristics when the electric strengths change. This section is to demonstrate that the relationship between electric strength and damping characteristics is the same as that between electric strength and CIF. Therefore, CIF, which is more easier to obtain, can be used to analyze the effect of electric strength on the risk of SSR.
Define Zone 1 as no SSR risk area and its sub-synchronous damping is greater than 1 . Zone 2 is the weak damping zone whose damping is within $[-1,1]$, considering the calculation error. Zone 3 is the risk zone where the damping is below -1 . Figure 4 shows the 3 zones with each point of $\left(X_{\text {eq1 } 1}, X_{\text {eq2 }}, X_{t r}\right)$.

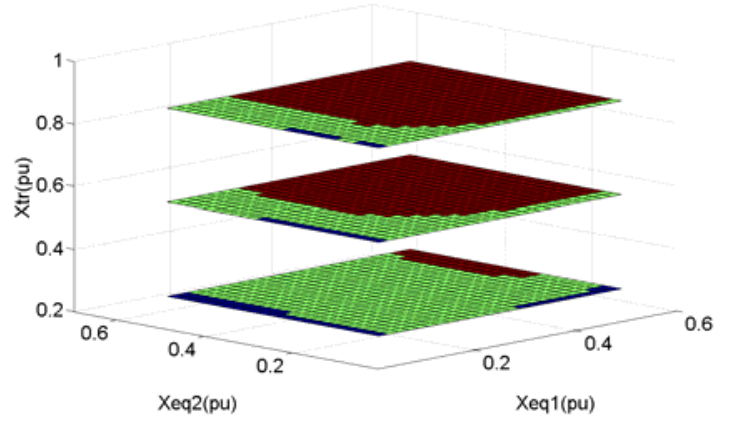

(a) 3 zones when $X_{t r}=0.2,0.6,0.8$ p.u.

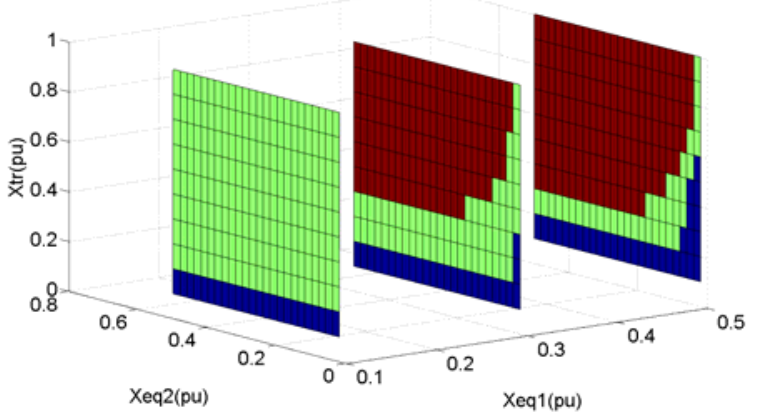

(b) 3 zones when $X_{\text {eq } 1}=0.1,0.3,0.5$ p.u.

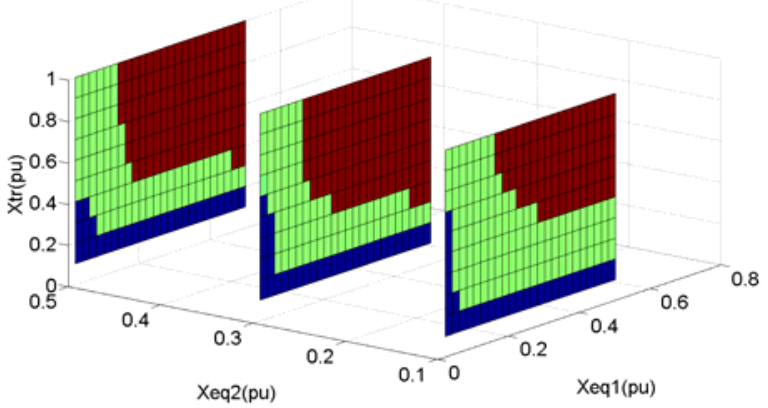

(c) 3 zones when $X_{\text {eq } 2}=0.1,0.3,0.5$ p.u.

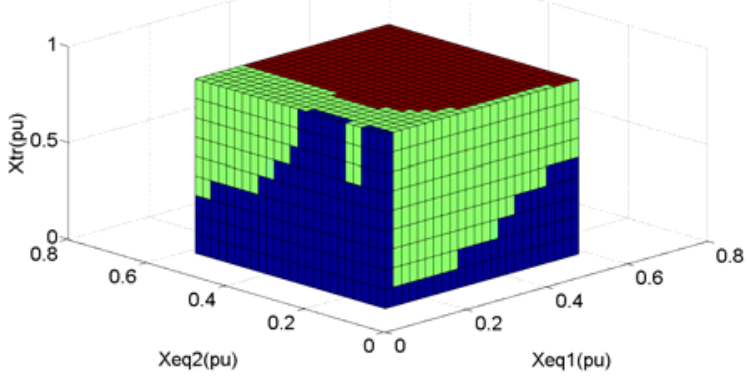

(d) overview

FIGURE IV. THE 3 ZONES (ZONE 1: BULE, ZONE 2: GREEN, ZONE 3 : RED) 
Figure 4(a) shows that the area of Zone 3 is small when $X_{t r}=0.2$. When $X_{t r}$ increases, the area of Zone 1 and Zone 2 reduce significantly and the risk of SSR increases.

Figure 4(b) shows that when $X_{\text {eq1 }}=0.1$, there is only Zone 1 and Zone 2, and the risk of SSR are very low. With the increase of $X_{\text {eq1 }}$, the area of Zone 3 increases, so does the risk of SSR.

Figure 4(c) shows that when $X_{\text {eq2 }}$ increases, the area of Zone 1 reduces while that of Zone 3 increases. This phenomenon means that the generator has a great opportunity to suffer SSR if the electric strength between Bus(1) and Bus(3) becomes weak.

Figure 4(d) gives an overview of the relationship between electric strength and damping characteristics. The stronger the electric strength between AC Buses is, the lower risk of SSR the generator suffers.

Compared Figure 3 and Figure 4, CIF can take the place of the damping characteristics to demonstrate the relationship between electric strength and SSR.

\section{B. SSR Test}

This section presents $3\left(X_{\text {eq } 1}, X_{\text {eq } 2}, X_{t r}\right)$ points (listed at Table 3 ) which are located at Zone 1 , Zone 2 and Zone 3 respectively. Frequency spectrum analysis, damping characteristics and shaft torque are presented to prove that strong electric strength is critical for the generator to avoid the risk of SSR.

TABLE III. PARAMETERS OF ELECTRIC STRENGTHS

\begin{tabular}{cccccc}
\hline \hline Case & $X_{\text {eq1 }}(\mathrm{pu})$ & $X_{\text {eq2 }}(\mathrm{pu})$ & $X_{\text {tr }}(\mathrm{pu})$ & CIF & ZONE \\
\hline 1 & 0.03 & 0.03 & 0.013 & 0.03 & 1 \\
2 & 1.56 & 0.06 & 1.287 & 0.24 & 2 \\
3 & 1.56 & 3.88 & 1.287 & 4.57 & 3 \\
\hline
\end{tabular}

Figure 5 shows SSR test results with different electric strengths.

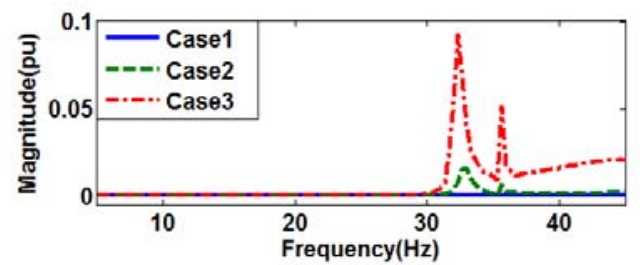

(a) Frequency spectrum analysis of terminal voltage

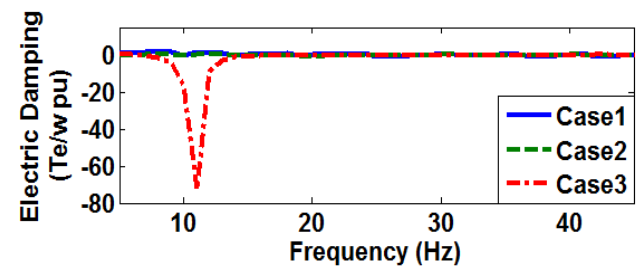

(b) Damping characteristics (overview)

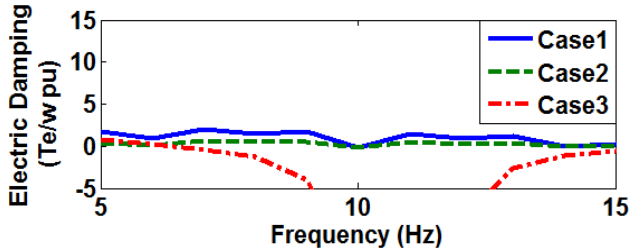

(c) Damping characteristics (magnified)

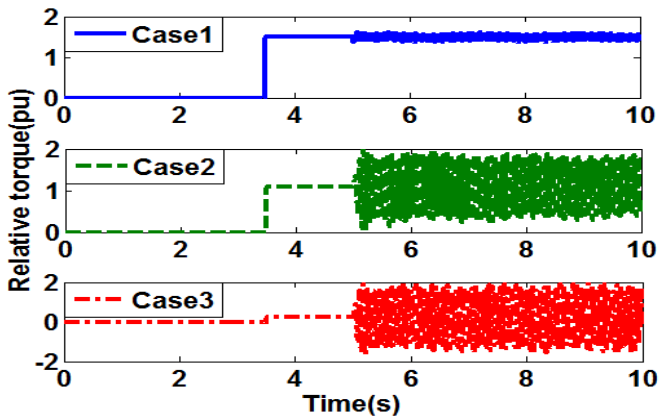

(d) Time domain simulation of SSR

FIGURE V. SIMULATION TESTS OF SSR

Figure 5(a) shows the magnitudes of terminal voltage at sub-synchronous frequency component. In Case 1 there is no sub-synchronous disturbance at the terminal voltage while Case 2 and Case 3 have at disturbance energy at $37.5 \mathrm{~Hz}$.

Figure 5(b) shows the damping characteristics of the 3 cases and Figure 5(c) are the amplified part of Figure 5(b). At $12.5 \mathrm{~Hz}$, the damping of Case 1 is positive while that of the other cases are negative.

Figure 5(d) are the time domain simulation of the SSR for the 3 cases. There is dramatic SSR in case 2 and 3 while no SSR threat in case 1.

Therefore, the CIF can be used to analyze the risk of SSR instead of damping characteristics. Strong electric strength can assist the generator to avoid the SSR risk.The proper range of electric strength are the group of $\left(X_{e q 1}, X_{e q 2}, X_{t r}\right)$ points in Zone 1.

\section{CONCLUSIONS}

This paper analysis the relationship between electric strength and the risk of SSR by using the CIF indicator. The computing process for forecasting risk of SSR is simplified because CIF is easier to obtained rather than the damping characteristics. Therefore, the proposed analysis method is more practical and convenient.

Strong electric strength between AC Buses is helpful to reduce risk of SSR. The proper range of electric strength is the group of $\left(X_{e q 1}, X_{e q 2}, X_{t r}\right)$ points in Zone 1 where the SSR will not happen.

\section{ACKNOWLEDGMENT}

This paper is supported by the Science and Technology project of State Grid Company of China "Research on key technology of series subsynchronous oscillation suppressor" (GEIRI-DL-71-18-005). 


\section{REFERENCES}

[1] Subsynchronous Resonance Working Group of the System Dynamic Performance Subcommittee, "Reader's guide to subsynchronousresonance,’IEEE Trans. PowerSyst., vol. 7, no.1, pp. 150-157, 1992.

[2] IEEE SSR Working Group, “Terms, definitions and symbols for subsynchronousoscillation,"IEEE Trans. Power App. Syst., vol. PAS104, no.6, pp.1326-1334, 1985.

[3] D.N.Walker and et al, "Resultsof subsynchronoustest at Mohave[J],’IEEE Trans. Power App.Syst, vol. PAS-94, no. 5, pp. 18781886, 1975

[4] N. Prabhu and et al, "Investigation of subsynchronous resonance with VSC-based HVDC transmission system,"IEEE Trans. Power Del., vol. 24, no. 1, pp. 433-440, 2009.

[5] K.R.Padiyar and et al, "Design and performance evaluation of subsynchronous damping controller with STATCOM," IEEE Trans. Power Del., vol.21, no.3, pp. 1398-1406, 2006.

[6] M.Bongiorno and et al, "A novel control strategy for subsynchronous resonance mitigation using SSSC,” IEEE Trans. Power Del., vol. 23, no. 2, pp. 1033-1041, 2008.

[7] D,Rai and et al.,"Damping inter-area oscillations using phase imbalanced series compensation schemes,"IEEE Trans. Power Syst., vol. 26, no. 3, pp. 1753-1761, 2011.

[8] L. L. Fan and et al, "Modeling of DFIG-Based wind farms for SSR analysis,” IEEE Trans. Power Del., vol.25, no.4, pp.2073-2083, 2010.

[9] D.Rai and et al.,"Enhancement of power system dynamics using a phase Canay1M, "A novel approach to the torsional interaction and electrical damping of the synchronous machine Part I:Theory,Part II:Application to An Arbitrary Network,"IEEE Trans. Power App. and Syst., PAS-101, no. 10, pp. 3630-3647, 1982.

[10] B.L.Agrawal and et al, "Use of frequency scanning techniques for subsynchronous resonance analysis,”IEEE Trans. Power App. Syst., vol. 98, no. 2, pp. 341-349, 1979.

[11] N.Johansson and et al, “ A comparison of different frequency scanning methods for study of subsynchronous resonance,"IEEE Trans. Power Syst., vol. 26, no. 1, pp. 356-363, 2011.

[12] Yaonan Yu, "Power system dynamics," Lecture Notes. University of British Columbia, Vacouer, B.C., Canada, pp. 1970-1976.

[13] P. Kundur, Power system stability and control, New York: McGraw Hill, pp. 1025-1072, 1994.

[14] I. M. Canay, "A novel approach to the torsional interaction and electrical damping of the synchronous machine part I: Theory", IEEE Trans. Power App. Syst., vol. PAS-101, no. 10, pp. 3630-3638, 1982.

[15] I. M. Canay, "A novel approach to the torsional interaction and electrical damping of the synchronous machine part II: Application to an arbitrary network", IEEE Trans. Power App. Syst., vol. PAS-101, no. 10, pp. 3639-3647, 1982.

[16] H. F. Li and et al., "Screening technique for identifying the risk of SSR", IET G.T.\&D., vol. 10, no. 7, pp. 1589-1596, 2016. 